\title{
Representation of spatial and temporal variability of daily wind speed and of intense wind events over the Mediterranean Sea using dynamical downscaling: impact of the regional climate model configuration
}

\author{
M. Herrmann ${ }^{1}$, S. Somot ${ }^{2}$, S. Calmanti ${ }^{3}$, C. Dubois ${ }^{2}$, and F. Sevault ${ }^{2}$ \\ ${ }^{1}$ IRD, LEGOS, UMR5566, CNRS - CNES - IRD - Université de Toulouse, Toulouse, France \\ ${ }^{2}$ CNRM/GAME, CNRS - Météo-France, Toulouse, France \\ ${ }^{3}$ UTMEA, ENEA, Roma, Italy
}

Received: 26 October 2010 - Revised: 28 March 2011 - Accepted: 3 June 2011 - Published: 19 July 2011

\begin{abstract}
Atmospheric datasets coming from long term reanalyzes of low spatial resolution are used for different purposes. Wind over the sea is, for example, a major ingredient of oceanic simulations. However, the shortcomings of those datasets prevent them from being used without an adequate corrective preliminary treatment. Using a regional climate model (RCM) to perform a dynamical downscaling of those large scale reanalyzes is one of the methods used in order to produce fields that realistically reproduce atmospheric chronology and where those shortcomings are corrected. Here we assess the influence of the configuration of the RCM used in this framework on the representation of wind speed spatial and temporal variability and intense wind events on a daily timescale. Our RCM is ALADIN-Climate, the reanalysis is ERA-40, and the studied area is the Mediterranean Sea.

First, the dynamical downscaling significantly reduces the underestimation of daily wind speed, in average by $9 \%$ over the whole Mediterranean. This underestimation has been corrected both globally and locally, and for the whole wind speed spectrum. The correction is the strongest for periods and regions of strong winds. The representation of spatial variability has also been significantly improved. On the other hand, the temporal correlation between the downscaled field and the observations decreases all the more that one moves eastwards, i.e. further from the atmospheric flux entry. Nonetheless, it remains $\sim 0.7$, the downscaled dataset reproduces therefore satisfactorily the real chronology.
\end{abstract}

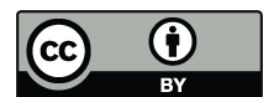

Correspondence to: M. Herrmann (marine.herrmann@ird.fr)
Second, the influence of the choice of the RCM configuration has an influence one order of magnitude smaller than the improvement induced by the initial downscaling. The use of spectral nudging or of a smaller domain helps to improve the realism of the temporal chronology. Increasing the resolution very locally (both spatially and temporally) improves the representation of spatial variability, in particular in regions strongly influenced by the complex surrounding orography. The impact of the interactive air-sea coupling is negligible for the temporal scales examined here. Using two different forcing datasets induces differences on the downscaled fields that are directly related to the differences between those datasets. Our results also show that improving the physics of our RCM is still necessary to increase the realism of our simulations. Finally, the choice of the optimal configuration depends on the scientific objectives of the study for which those wind datasets are used.

\section{Introduction}

Energy transfers that occur at the air-sea interface drive the dynamics of the surface oceanic mixed layer. These transfers are associated with momentum, turbulent and radiative fluxes in which wind plays a major role. Wind is indeed the driver of wind stress. It is also a major forcing of the turbulent heat exchanges, since the latent and the sensible heat fluxes as well as the turbulent transfer coefficient directly depend on the wind speed. Wind forcing (speed and direction) is therefore a major ingredient of oceanic numerical simulations. Compared to wider and flatter ocean areas, the quality of the wind forcing is even more crucial when looking to

Published by Copernicus Publications on behalf of the European Geosciences Union. 
simulate the Mediterranean Sea circulation. This is due to the complexity of the atmospheric flow over the Mediterranean Sea, which is strongly influenced by the complex surrounding orography. The orography plays a particularly important role during intense wind events because it channels local winds: mountains and valleys such as the Massif Central, the Rhone valley, the Alps, the Dinaric Alps, the Atlas mountain and the Turkish mountains are responsible for the intensification of strong northerly winds like the Mistral, Tramontane, Bora, Harmattan and Etesians. This has been already underlined by numerous papers in the recent literature: after a pioneer work by Myers et al. (1998), Sotillo et al. (2005), Ruti et al. (2007), and Herrmann and Somot (2008) demonstrated the role of the horizontal resolution in the representation of the wind over the Mediterranean Sea. Herrmann and Somot (2008), Beuvier et al. (2010) and Béranger et al. (2010) have illustrated the impact of high-resolution atmospheric forcing $(50 \mathrm{~km})$ on oceanic processes such as ocean deep convection and the Eastern Mediterranean Transient.

Herrmann and Somot (2008) and Pettenuzzo et al. (2010) have shown that the underestimation of wind speed in the ERA-40 reanalysis (Simmons and Gibson, 2000) has a strong impact on the air-sea fluxes over the Mediterranean area. For example, applying a statistical wind correction to an ERA-40 wind field, Pettenuzzo et al. (2010) increased the Mediterranean Sea latent heat loss by $24 \%$ and the sensible heat loss by $17 \%$ in average over the 1985-2001 period. Applying a dynamical downscaling technique to ERA-40, Herrmann and Somot (2008) increased the wind stress by $32 \%$ and heat loss by $10 \%$ over the Gulf of Lions area for winter 1986-1987. Moreover, in this study the percentage of change was stronger for the most intense events $(+17 \%$ for the 99 th quantile of the daily net heat loss and $+58 \%$ for the maximum peak). Recently, Romanou et al. (2010) have shown the role of the wind field spatial pattern in driving the evaporation spatial pattern over the Mediterranean area, specially for the spatial maxima. Finally, the wind field high-resolution spatial patterns and high temporal frequency could influence the Mediterranean air-sea exchanges and oceanic processes.

To force Mediterranean Sea oceanic models for shortterm run or process studies, modellers usually apply highresolution weather forecast model analysis (Béranger et al., 2005; ?). However, performing realistic long-term Mediterranean oceanic simulations without temporal inconsistency, reanalysis of surface atmospheric variables (NCEP; Kalnay et al., 1996, ERA-15; Gibson et al., 1997, ERA-40) are the natural choice despite their low spatial resolution. They have been extensively used for Mediterranean Sea modelling (Myers et al., 1998; Lascaratos et al., 1999; Castellari et al., 2000; Rupolo et al., 2003; Demirov and Pinardi, 2007; Béranger et al., 2010). The inaccuracy of those wind fields, especially during intense meteorological events, was then proved (see above) and the ocean modellers started to apply various correcting techniques. Ad hoc empirical corrections (Demirov and Pinardi, 2007; Herrmann et al., 2008; Sannino et al.,
2009), statistical corrections using reference in-situ or satellite observations to fit spatio-temporal correction coefficients (Pettenuzzo et al., 2010) and dynamical downscaling techniques (Sotillo et al., 2005; Herrmann and Somot, 2008; Artale et al., 2009; Beuvier et al., 2010; Herrmann et al., 2010; Sanchez-Gomez et al., 2011) were developed. The last technique consists in driving a regional climate model (RCM) by a reanalysis in order to keep a synoptic scale chronology in agreement with the reanalysis and let the RCM invent the small scale physics necessary for a better representation of the wind field. The driving can be applied only to the large scales in spectral space or at the lateral boundary of a limited area model (LAM). The spectral method is used in Herrmann and Somot (2008) to create the so-called ARPERA Mediterranean Sea forcing dataset used in Beuvier et al. (2010) and Herrmann et al. (2010) to study deep water formation. The lateral boundary driving of a LAM is used in Artale et al. (2009) and Sanchez-Gomez et al. (2011). Sotillo et al. (2005) combine both methods using the spectral nudging technique (von Storch et al., 2000) in an LAM. The dynamical downscaling technique is very promising since it provides very good temporal chronology, longterm temporal homogeneity, high spatial and temporal resolution and physical consistency for all the atmospheric variables at the same time. This technique can also be applied to coupled RCM to take into account air-sea feedbacks (Artale et al., 2009). Up-to-now and for the Mediterranean area, the available multi decadal downscaled datasets have a resolution of 50 to $25 \mathrm{~km}$ (Sanchez-Gomez et al., 2011). However, Langlais et al. (2009) and Lebeaupin Brossier et al. (2011) demonstrated the potential interest of higher spatial resolution (respectively 18 and $7 \mathrm{~km}$ ) at least over the Gulf of Lions area. This very promising technique is also used in other regional ocean areas around the world (Baltic Sea, Gulf of Mexico, Arctic Sea, Chili-Peru upwelling).

Despite its intrinsic qualities, the downscaling technique introduces a new uncertainty linked with the use of the downscaling model and technique. No detailed evaluation of this uncertainty has been done until now over the Mediterranean area. The goal of our study is to contribute to the understanding and assessment of this uncertainty. Uncertainties related to downscaling can be divided into two components. The first type of uncertainty is related to the choice of the $\mathrm{RCM}$ for a given setting (i.e. for a given domain, resolution, driving method and driving reanalysis). This aspect requires a coordinate international research project involving several RCMs following the same framework. The European project ENSEMBLES (http://ensembles-eu.metoffice.com/) fulfills those requirements and its RCMs database is currently used for such a study by Sanchez-Gomez et al. (2011) and at GKSS (Ivonne Anders, pers. communication). In the future the HyMeX-MedCORDEX simulations should also provide useful information (http://www.hymex.org, http://copes.ipsl. jussieu.fr/RCD_CORDEX.html). The second type of uncertainty is related to the configuration of a given RCM used to 
perform the dynamical downscaling (i.e. size of the domain, resolution, use of spectral nudging, air-sea coupling, choice of the driving reanalysis). The current paper deals with this aspect: the influence of the RCM design.

In the current paper we investigate the impact of the design of a given RCM on its downscaling ability using the limitedarea RCM developed at Météo-France/CNRM, ALADINClimate. We focus on the Mediterranean Sea daily wind speed field. We test the influence of the spatial domain extension, of the spatial resolution, of the driving dataset, and of the use of the spectral nudging and interactive airsea coupling techniques. QuikSCAT satellite products available daily and over the whole Mediterranean are used as a reference to evaluate the quality of the various model configurations. QuikSCAT dataset, the ALADIN-Climate RCM and the simulations performed for this study are described in Sect. 2. We present the results in Sect. 3. Our main conclusions are summarized in Sect. 4.

\section{Tools: data and model}

\subsection{Sea wind data: QuikSCAT}

Satellite observations of wind speed over the sea are provided twice daily by QuikSCAT LEVEL 3 dataset with a $0.25^{\circ} \sim 25 \mathrm{~km}$ resolution ?available at: ftp://podaac.jpl. nasa.gov/allData/quikscat/L3/jpl/hdf/,)[]quikscat. Comparing those data with in-situ data provided by buoy-mounted anemometers, Ruti et al. (2007) demonstrated the ability of the QuikSCAT instrument in retrieving the dynamics of the instantaneous wind fields, in particular the in-situ variability, for both the direction and the speed. Bentamy et al. (2009) used QuikSCAT dataset to evaluate wind products made by merging real time remotely sensed winds and ECMWF analyses at global and regional scales. Chronis et al. (2010) used them to depict the key seasonal characteristics of the extreme wind states of the Mediterranean and Black Seas. Neither the ERA-40 nor ERA-Interim assimilation systems use the QuikSCAT data.

What makes QuikSCAT satellite observations interesting compared to in-situ data is their very good spatial and temporal coverage. However QuikSCAT data are available at most twice a day. The daily timescale is therefore the finest scale that can be examined through this dataset. We first evaluated the representativeness of the daily wind speed obtained by averaging maximum two QuikSCAT values. For that, we compared QuikSCAT data with in-situ wind speed data obtained every hour from two buoys located in the Ligurian Sea (AZUR, $43.4^{\circ} \mathrm{N} ; 7.8^{\circ}$ E, see Fig. 1) and in the Gulf of Lions (LION, $42.1^{\circ} \mathrm{N} ; 4.7^{\circ} \mathrm{E}$ ). Those data, already used by Ruti et al. (2007), have been available since 7 December 2001 at LION and 1 May 1999 at AZUR. For each buoy, we took into account days for which both in-situ and satellite data were available (1714 days for AZUR, 1584 days for LION). On Fig. 2b, we compared at each buoy location QuikSCAT daily wind speed with the daily average of 24 hourly in-situ values over each day. The mean bias of the average daily QuikSCAT wind speed compared to the average daily buoy wind speed was equal to $0.5 \%$ for LION and $2.5 \%$ for AZUR, the RMSE is equal to respectively $26 \%$ and $33 \%$, and the correlation to 0.92 for LION and 0.88 for AZUR with a significant level equal to 1 in both cases. More precisely, QuikSCAT slightly underestimates weak values and overestimates strong values of daily wind speed as shown by the quantile-quantile plots (hereafter $Q$ $Q$ plots). This is related to the fact that we used maximum 2 values for QuikSCAT while we used 24 values for the buoy, which induces a stronger smoothing of the very strong/weak values. Between 0 and $17 \mathrm{~m} \mathrm{~s}^{-1}$, i.e. over a range that contains the 95th percentile for both buoys and in general over the whole basin (see Fig. 1), the biases and RMSE are however smaller than $4 \%$ and $38 \%$ respectively. As we will see later, the biases between QuikSCAT and ALADIN-Climate or ERA-40 are much larger than those biases (respectively $17 \%$ and $26 \%$ in average over the Mediterranean Sea). The RMSE between QuikSCAT and ALADIN-Climate or ERA40 (respectively $42 \%$ and $43 \%$ ) are also larger, though of the same order. Finally, the correlations between QuikSCAT and ALADIN-Climate (0.69) or ERA-40 (0.78) are significantly smaller. QuikSCAT therefore represents correctly daily wind speed variability and can be legitimately used as a reference when examining the representation of wind speed daily variability over the Mediterranean in ALADIN, for weak, average and strong winds. Exceptional winds (larger than $17 \mathrm{~m} \mathrm{~s}^{-1}$, i.e. than the 99th percentile) should be examined with caution, but are beyond the scope of this study: individual studies would be more relevant than statistical studies to examine such events.

In the following, we will compare the simulations and the data over the period covered simultaneously by QuikSCAT, ERA-40 and ERA-Interim, i.e. 2000-2001. To evaluate the representativeness of the period 2000-2001 in terms of daily wind speed variability, we compare the distribution of daily wind speed over the period 2000-2001 and the whole period of QuikSCAT availability, from 19 July 1999 through 21 November 2009 (Fig. 2a). Both distributions are extremely close over the whole spectrum of wind speed: the $Q-Q$ plot is very close to the identity line, the difference of the average value between the period 2000-2001 and the whole period is equal to $0 \%$, the difference of RMS to $-3 \%$ and the difference of 95th percentile to $-2 \%$. 2000-2001 is therefore representative of the daily wind speed variability.

Figure 1 presents the data availability, the average, the standard deviation and the 95th percentile of QuikSCAT daily wind speed over the 2000-2001 period in the Mediterranean Sea. The data availability over 2000-2001 and over the Mediterranean Sea is good in general. For $80 \%$ of the points, data are available more than $90 \%$ of the time. However, very close to the coast the availability is reduced, and 

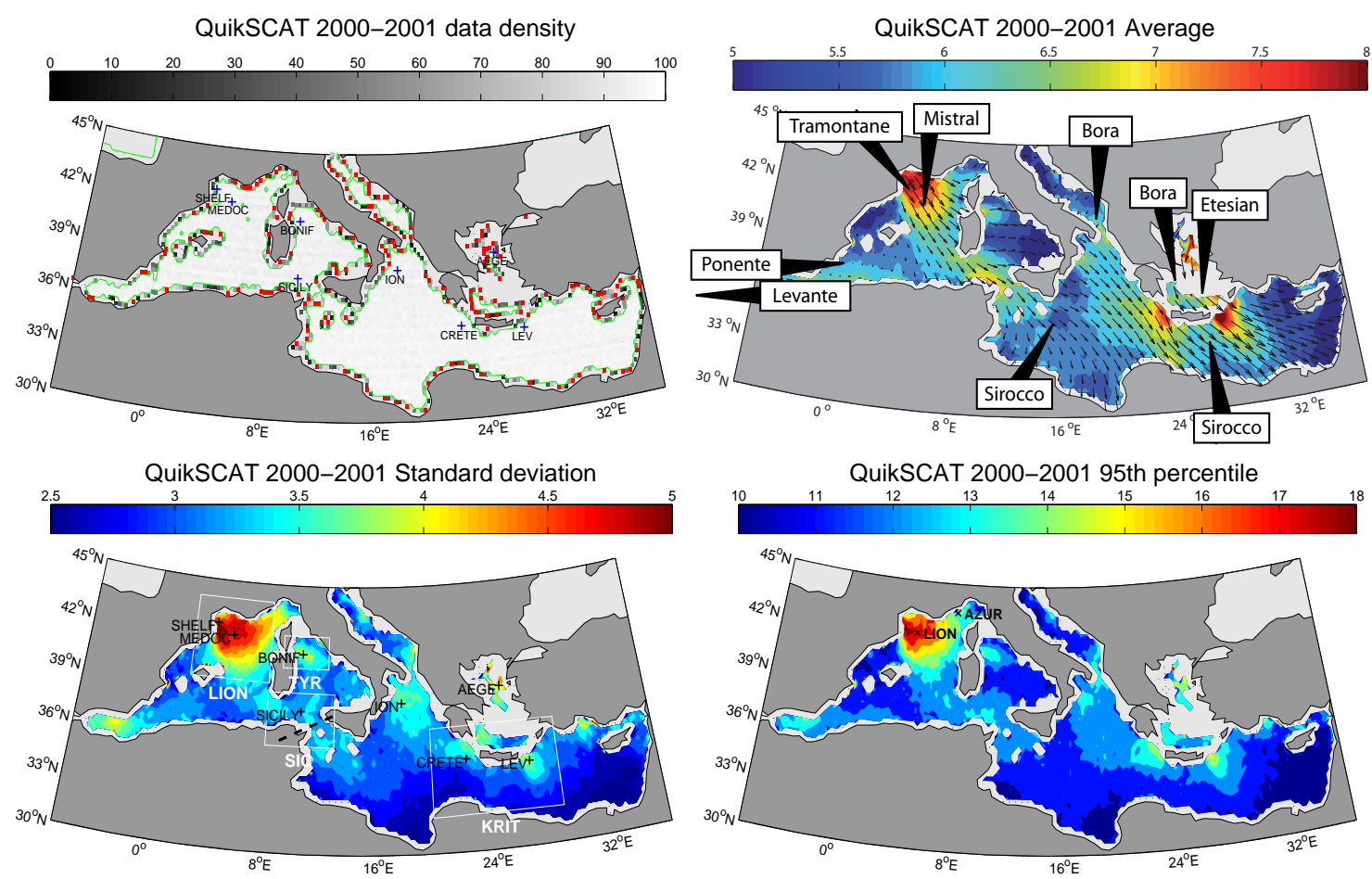

Fig. 1. Data availability (percentage of days with no missing data during 2000-2001), average wind speed and direction, standard deviation and 95th percentile of the daily wind speed over 2000-2001 in QuikSCAT. In the top-left panel, the green line shows the contour of the area where data are available more than $90 \%$ of the days, i.e. more than 656 days, and left squares indicate points for which data are available less than $10 \%$ of the the time, i.e. less than 73 days. Names of the main winds over the Mediterranean are indicated on the top-right panel (adapted from Chronis et al., 2010), position of the points and boxes used in this study on the bottom-left panel, and position of the LION and AZUR buoys on the bottom-right panel. The dashed line indicates the frontier between the Western and the Eastern basins. Unit: $\mathrm{m} \mathrm{s}^{-1}$.

for $5 \%$ of the points, data are available less than $10 \%$ of the time. When performing our diagnostics, we deal with those missing values by not taking the corresponding day and point into account, neither for the QuikSCAT dataset nor for the times series obtained thanks to the simulations presented below, in order to obtain comparable numbers. The regions of most intense winds and strong variability are the Gulf of Lions and the east of Corsica (Bonifacio Strait), the Sicily strait, the south of the Adriatic Sea and north of Ionian Sea, the regions southwest and southeast of Crete and the Aegean Basin. For the following analysis of the different simulations, we selected eight points located in the regions of strong winds: SHELF, MEDOC, BONIF, SICILY, ION, CRETE, LEV and AEGE (Fig. 1). We made sure to select points for which data were available at least $90 \%$ of the time. We also selected four boxes (LION, TYR, SIC and KRIT, Fig. 1) that covered the areas of strong winds in order to examine the ability of the model to reproduce wind speed spatial patterns in those regions.

\subsection{Model and simulations}

\subsubsection{The ALADIN-Climate RCM}

We use the limited-area atmosphere RCM ALADIN-Climate (Radu et al., 2008; Déqué and Somot, 2008; Farda et al., 2010; Colin et al., 2010). Here we use the version 5 described in Colin et al. (2010) whereas the other cited papers used the version 4. ALADIN-Climate shares the same dynamical core as the cycle 32 of its weather forecast ALADIN counterpart and the same physical package as the version 5 of the GCM ARPEGE-Climate (Déqué, 2010, http://www.cnrm. meteo.fr/gmgec/arpege-climat/ARPCLI-V5.1/index.html).

ALADIN-Climate is a bi-spectral RCM with a semi-implicit semi-lagrangian advection scheme. Its configuration includes a 11-point wide bi-periodization zone in addition to the more classical 8 point relaxation zone. This so-called extension zone allows the computation of the fast-Fourier transforms for the spectral-to-grid point space computation. More details can be found in Farda et al. (2010). We do not want to detail here all the physical parameterizations of ALADIN-Climate but only to recall that in this version, the planetary boundary layer turbulence physics is based on Louis (1979) and the interpolation of the wind speed 
a)

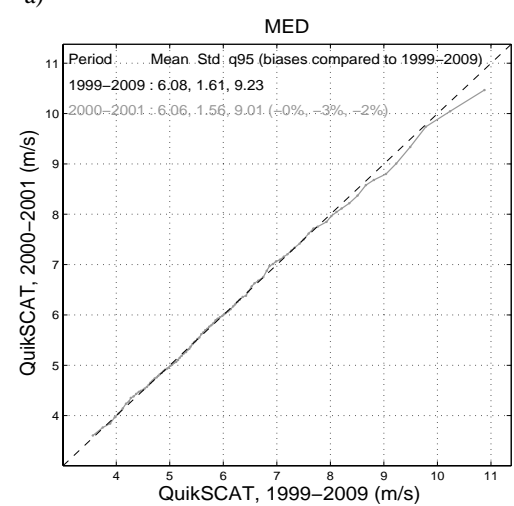

b)
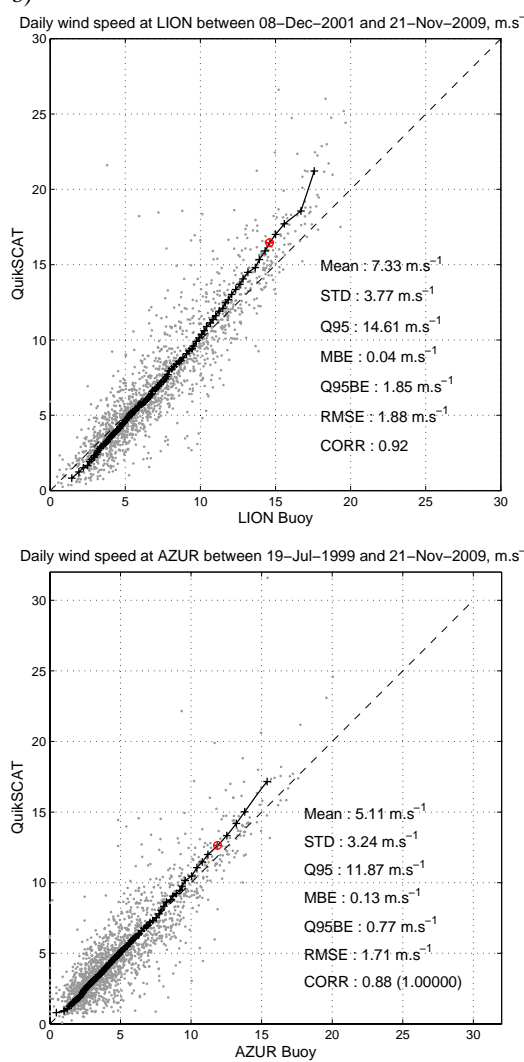

Fig. 2. Representativeness of daily wind variability by QuikSCAT. (a) $Q-Q$ plot of QuikSCAT daily wind speed distribution between 1 January 2000 and 31 December 2001 compared to distribution between 19 July 1999 and 21 November 2009. (b) Scatterplot and $Q-Q$ plot of QuikSCAT daily wind speed compared to average insitu daily wind speed at buoys LION and AZUR over the periods during which satellite and in-situ data are both available. Values of the average, standard deviation and 95th percentile of the daily wind speed at the buoys are indicated, as well as the mean bias (MBE), the 95th percentile bias (Q95BE), the RMSE and the correlation of QuikSCAT daily wind speed compared to the buoy daily wind speed. Red circles indicate the value of the 95 th percentile. Unit: $\mathrm{ms}^{-1}$. from the first layer of the model (about $30 \mathrm{~m}$ ) to the $10 \mathrm{~m}$ height follows Geleyn (1988). The version 5 used here is also used in the framework of the regional Med-CORDEX exercise and is close to the ARPEGE-Climate version used for the next CMIP5 exercise. ALADIN-Climate version 4 was used for the European ENSEMBLES project in which it was inter-compared with the state-of-the art of the European RCMs at 50 and $25 \mathrm{~km}$ (Christensen et al., 2008; Sanchez-Gomez et al., 2008; Christensen et al., 2010).

Different configurations of this model can be used. They are obtained by varying the spatial resolution, the size and position of the domain, and the dataset used for the large scale forcing. More complex and unusual options are also available as the use of spectral nudging and interactive airsea coupling techniques.

\subsubsection{The spectral nudging technique}

All details concerning spectral nudging can be found in Radu et al. (2008) and Colin et al. (2010). This technique was first used for regional climate purposes by von Storch et al. (2000) and Biner et al. (2000). It allows a better constraint of the large-scales of an LAM that is usually driven only at its lateral boundaries. In the spectral space, a relaxation towards the driving model (here the reanalysis) is applied to the largescales of some of the prognostic variables. In ALADINClimate, the following parameters are tunable: the choice of the nudged variables, the strength of the nudging (which depends on the variable and on the altitude), the threshold of the large-scales to be nudged. In the current study we nudged the following prognostic variables: temperature, wind vorticity, wind divergence and logarithm of the surface pressure. The maximum e-folding time depends on the variables $(6 \mathrm{~h}$ for the vorticity, $24 \mathrm{~h}$ for the logarithm of the surface pressure, the specific humidity and the temperature, $48 \mathrm{~h}$ for the divergence) following the setting of Guldberg et al. (2005). The maximum e-folding time is reached above $700 \mathrm{hPa}$ and for scales larger than $1280 \mathrm{~km}$. The nudging is linearly decreasing between 700 and $850 \mathrm{hPa}$ in altitude and between 1280 to $640 \mathrm{~km}$ for the horizontal scales. The atmospheric boundary layer and the scales not represented in ERA-40 are not nudged.

\subsubsection{The interactive air-sea coupling technique}

ALADIN-Climate can also be used in a fully interactive mode coupled with an eddy-permitting Mediterranean Sea ocean model. This mode follows the setting of Somot et al. (2008), except that the ARPEGE-Climate stretched-grid climate model was replaced by the ALADIN-Climate limitedarea RCM and the former OPAMED8 model was replaced by NEMOMED8 (Madec, 2008; Sevault et al., 2009; Beuvier et al., 2010). The coupling is regional: it covers only the Mediterranean Sea area. We use the OASIS coupler version 3 (Valcke, 2006). The coupling frequency is equal to one day. 
The RCM provides the daily radiative, turbulent and momentum fluxes to the ocean model and the ocean model provides its SST to the RCM. Following the setting of Beuvier et al. (2010), the rivers, the Black Sea freshwater inputs and the Atlantic water characteristics are climatological.

\subsubsection{The large scale driving: ECMWF reanalysis}

Re-analyses of multi-decadal series of past observations are used, among others, to provide boundary conditions in the framework of long term oceanic and atmospheric numerical simulations. The ERA-40 reanalysis covers the period 19582001 and is widely used by the modellers. It was obtained in 2002 using the three dimensional variational assimilation technique and a T159 spectral truncation version $(\sim 125 \mathrm{~km})$ of the Integrated Forecasting System developed jointly by ECMWF and Météo-France. Outputs were produced every six hours.

The ERA-Interim reanalysis (Berrisford et al., 2009) covers the period 1989-today. The ERA-Interim data assimilation system uses a 2006 release of the Integrated Forecasting System, which contains many improvements both in the forecasting model and analysis methodology relative to ERA-40, in particular the resolution (T255 $\sim 80 \mathrm{~km}$, http://www.ecmwf.int/research/era/do/get/era-interim).

\subsubsection{ALADIN-Climate simulations}

In the current study, our goal is to estimate the impact of the design of ALADIN-Climate RCM on the representation of wind speed over the Mediterranean Sea. The following elements are tested using different model configurations:

- the choice of the spatial resolution,

- the choice of the extension of the spatial domain,

- the impact of the spectral nudging technique,

- the impact of the interactive air-sea coupling technique,

- the choice of the driving reanalysis.

For this, we have performed 7 simulations (MED125, MED50, MED10, WMED50, MED50SN, MED50AO, MED50Int). Depending on the simulation, we used 2 different domains (MED and WMED), 3 resolutions (125 km, $50 \mathrm{~km}, 10 \mathrm{~km}$ ), 2 large scale driving sets (ERA-40 and ERAInterim), the air-sea coupling (AO) and the spectral nudging (SN). The orography of each of the different grids used here is presented in Fig. 3, as well as the orography of ERA-40 and ERA-Interim. MED50 is the control simulation with which all the other simulations will be compared. The characteristics of each simulations are summarized in Table 1. We examine those simulations during the period 2000-2001. All simulations start from an ERA40 initial state for the 3-D prognostic variables of the model (atmosphere and land surface) and cover the period January 1998 to December 2001. The first two years are considered as spinup, allowing the land water content to reach its equilibrium. Land surface parameters and aerosols concentration are updated every month following a climatological seasonal cycle coming from observations. The sea surface temperatures (except for the Mediterranean Sea in the coupled system) and the sea ice limit (Black Sea) are updated every month with a seasonal and interannual variability following ERA-40 SST and sea ice analysis. ERA-Interim and ERA-40 SST are identical at the monthly time scale over the period 2000-2001. The atmosphere lateral boundary conditions of ALADINClimate are vertically and horizontally interpolated from the ERA-40 and ERA-Interim 3-D reanalyzes every $6 \mathrm{~h}$ onto the ALADIN-Climate model grids. The simulation with the coupled system has the same set-up as the non-coupled experiment except for the spin-up period that has to be longer because of the long-term memory of the regional ocean components. Multi-decadal spin-up is then required as shown in Somot et al. (2006) and already applied in Somot et al. (2008). We then carried out a 40-yr long spin-up for the coupled system from August 1960 to December 1999 using ERA40 as lateral boundary conditions before starting the 2000-2001 simulations. There is no nudging for the atmosphere and ocean in the coupled simulation. For all simulations both components of instantaneous wind velocity are stored every $6 \mathrm{~h}$.

We examine those simulations for the period 2000-2001, which corresponds to the period covered simultaneously by QuikSCAT, ERA-40 and ERA-Interim.

\section{Results: representation of daily wind speed spatial and temporal variability over the Mediterranean Sea during 2000-2001}

To investigate the performances of the dynamical downscaling and the impact of the model configuration regarding the representation of wind speed variability over the Mediterranean Sea on a daily timescale, we performed a set of diagnostics.

First, Fig. 4 shows the average over 2000-2001 of the daily wind speed for QuikSCAT, the reanalysis and each ALADIN-Climate simulation. Taking QuikSCAT as a reference, we then compute for each simulation the temporal correlation of the daily wind speed $V$ over 2000-2001, the bias ( $\overline{V-V_{\text {QuikSCAT }}}$ where the overbar indicates the average over 2000-2001), the RMSE (root mean square error, $\left.\sqrt{\left(V-V_{\text {QuikSCAT }}\right)^{2}}\right)$ and the bias of the 95th quantile $\left(q 95-q 95_{\text {QuikSCAT }}\right)$. We choose the 95 th quantile ( $q 95$ hereafter) as an index of intense events, because it corresponds to winds much stronger than the average (occurring only $5 \%$ of the times), but whose occurrence is still sufficient to be statistically significant (5\% of $2 \mathrm{yr}$ corresponds 

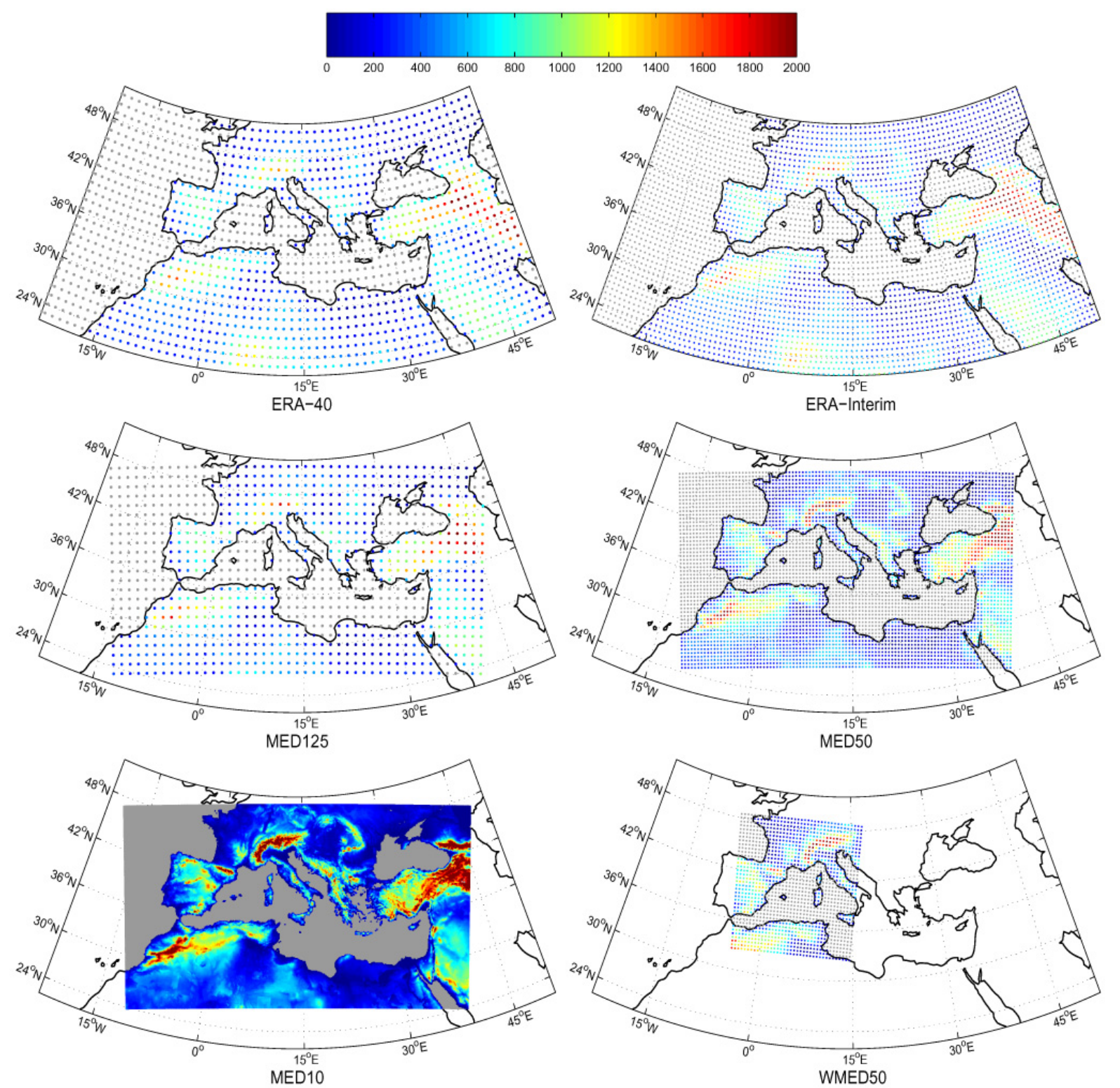

Fig. 3. Grid (points) and orography (colors, unit: m) of ERA-40, ERA-Interim and the grids used for our simulations.

Table 1. List and characteristics of the ALADIN-Climate simulations.

\begin{tabular}{llclll}
\hline NAME & Forcing & Resolution & Domain & $\begin{array}{l}\text { Spectral } \\
\text { Nudging }\end{array}$ & $\begin{array}{l}\text { A/O } \\
\text { coupling }\end{array}$ \\
\hline MED50 & ERA-40 & $50 \mathrm{~km}$ & MED & No & No \\
MED50SN & ERA-40 & $50 \mathrm{~km}$ & MED & Yes & No \\
MED50AO & ERA-40 & $50 \mathrm{~km}$ & MED & No & Yes \\
MED50Int & ERA-Interim & $50 \mathrm{~km}$ & MED & No & No \\
MED10 & ERA-40 & $10 \mathrm{~km}$ & MED & No & No \\
MED125 & ERA-40 & $125 \mathrm{~km}$ & MED & No & No \\
WMED50 & ERA-40 & $50 \mathrm{~km}$ & WMED & No & No \\
\hline
\end{tabular}



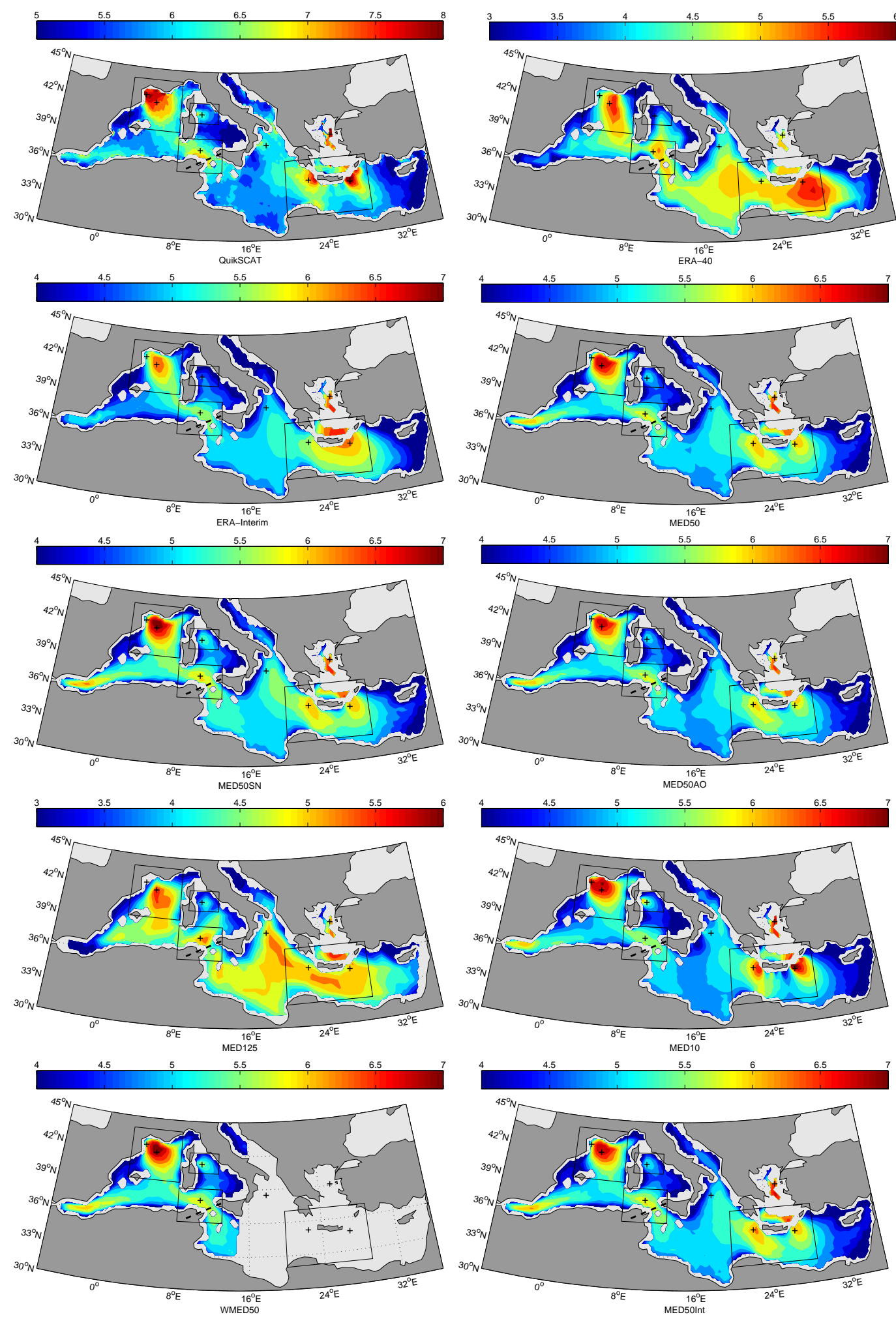

Fig. 4. Average over 2000-2001 of the daily wind speed $\left(\mathrm{m} \mathrm{s}^{-1}\right)$ in QuikSCAT, ERA-40, ERA-Interim and each ALADIN-Climate simulation. The colorbar is not always the same for each map but its amplitude is always the same in order to highlight the similarities/differences of spatial patterns. 
Table 2. Mean values over 2000-2001 and over the whole Mediterranean Basin for the bias, the RMSE, the temporal correlation and the 95th percentile bias of the daily wind speed compared with QuikSCAT for ERA-40, ERA-Interim and each ALADIN-Climate simulation. Percentages indicate the ratio relative to QuikSCAT mean value (for bias and RMSE) and $q 95$ value (for $q 95$ bias).

\begin{tabular}{lllll}
\hline \multicolumn{5}{l}{ QuikSCAT: mean value $=6.08 \mathrm{~m} \mathrm{~s}^{-1}$, standard deviation $\sigma=3.26 \mathrm{~m} \mathrm{~s}^{-1}, q 95=12.13 \mathrm{~m} \mathrm{~s}^{-1}$} \\
\hline & bias $\left(\mathrm{m} \mathrm{s}^{-1}\right)$ & RMSE $\left(\mathrm{m} \mathrm{s}^{-1}\right)$ & correlation & bias of $q 95\left(\mathrm{~m} \mathrm{~s}^{-1}\right)$ \\
\hline ERA-40 & $-1.61(-26 \%)$ & $2.58(43 \%)$ & 0.78 & $-3.23(-26 \%)$ \\
ERA-Interim & $-1.03(-17 \%)$ & $2.17(36 \%)$ & 0.80 & $-2.22(-18 \%)$ \\
\hline MED50 & $-1.01(-17 \%)$ & $2.55(42 \%)$ & 0.69 & $-1.73(-14 \%)$ \\
MED50SN & $-0.88(-15 \%)$ & $2.41(40 \%)$ & 0.72 & $-1.56(-13 \%)$ \\
MED50AO & $-1.06(-17 \%)$ & $2.56(42 \%)$ & 0.69 & $-1.81(-15 \%)$ \\
MED125 & $-1.57(-26 \%)$ & $2.94(49 \%)$ & 0.64 & $-2.74(-22 \%)$ \\
MED10 & $-1.01(-17 \%)$ & $2.52(42 \%)$ & 0.70 & $-1.85(-15 \%)$ \\
MED50Int & $-0.99(-16 \%)$ & $2.49(41 \%)$ & 0.71 & $-1.76(-14 \%)$ \\
\hline
\end{tabular}

Table 3. Mean values over 2000-2001 and over the Western Basin for the bias, the RMSE, the temporal correlation and the 95th percentile bias of the daily wind speed compared with QuikSCAT for ERA-40, ERA-Interim and each ALADIN-Climate simulation. Percentages indicate the ratio relative to QuikSCAT mean value (for bias and RMSE) and $q 95$ value (for $q 95$ bias).

\begin{tabular}{lllll}
\hline \multicolumn{5}{c}{ QuikSCAT: mean value $=6.15 \mathrm{~m} \mathrm{~s}^{-1}, \sigma=3.54 \mathrm{~m} \mathrm{~s}^{-1}, q 95=12.77 \mathrm{~m} \mathrm{~s}^{-1}$} \\
\hline & bias $\left(\mathrm{m} \mathrm{s}^{-1}\right)$ & RMSE $\left(\mathrm{m} \mathrm{s}^{-1}\right)$ & correlation & bias of $q 95\left(\mathrm{~m} \mathrm{~s}^{-1}\right)$ \\
\hline ERA-40 & $-1.83(-30 \%)$ & $2.84(46 \%)$ & 0.79 & $-3.73(-29 \%)$ \\
ERA-Interim & $-1.17(-19 \%)$ & $2.33(38 \%)$ & 0.81 & $-2.44(-19 \%)$ \\
\hline MED50 & $-1.02(-17 \%)$ & $2.58(42 \%)$ & 0.74 & $-1.77(-14 \%)$ \\
MED50SN & $-0.85(-14 \%)$ & $2.48(41 \%)$ & 0.75 & $-1.54(-12 \%)$ \\
MED50AO & $-1.02(-17 \%)$ & $2.57(42 \%)$ & 0.74 & $-1.78(-14 \%)$ \\
MED125 & $-1.78(-29 \%)$ & $3.09(51 \%)$ & 0.70 & $-3.13(-24 \%)$ \\
MED10 & $-1.00(-16 \%)$ & $2.54(42 \%)$ & 0.74 & $-1.79(-14 \%)$ \\
MED50Int & $-1.00(-16 \%)$ & $2.52(41 \%)$ & 0.76 & $-1.77(-14 \%)$ \\
WMED50 & $-0.91(-15 \%)$ & $2.39(39 \%)$ & 0.77 & $-1.71(-13 \%)$ \\
\hline
\end{tabular}

to 40 over 731 days). The average value of the bias, the RMSE, the temporal correlation and the bias of $q 95$ over the Mediterranean Sea, the Western Basin and the Eastern Basin are indicated respectively in Tables 2,3 , and 4 for each simulation. Values of the relative bias $\left(\frac{\overline{V-V_{\text {QuikSCAT }}}}{\overline{V_{\text {QuikSCAT }}}}\right)$, RMSE $\left(\frac{\sqrt{\left(V-V_{\text {QuikSCAT }}\right)^{2}}}{\overline{V_{\text {QuikSCAT }}}}\right)$ and $q 95$ bias $\left(\frac{\overline{q 95-q 95_{\text {QuikSCAT }}}}{\overline{q 95_{\text {QuikSCAT }}}}\right)$ are also indicated.

In order to examine how the model reproduces the distribution of wind events, we plot the $Q-Q$ plots between the simulations and QuikSCAT of the daily wind speed averaged over the whole Mediterranean, the Western Basin and the Eastern Basin (Fig. 5a). We also compute the $Q-Q$ plots for the points located in the regions of strong winds taking for each model grid the closest point (Fig. 5b). For each point, the mean values over 2000-2001 of the bias, the RMSE, the correlation and the $q 95$ bias are indicated in the legend. The correlation between the row vector $\boldsymbol{x}$ of model time series and the row vector $\boldsymbol{y}$ of QuikSCAT time series at each point is given by $\frac{\mathbf{C}_{x y}}{\sqrt{\mathbf{C}_{x x} \mathbf{C}_{y y}}}$ where $\mathbf{C}$ is the $2 \times 2$ covariance matrix between $\boldsymbol{x}$ and $\boldsymbol{y}$ defined by

$\mathbf{C}_{x x}=\frac{1}{n-1} \sum_{i=1}^{n}\left(\boldsymbol{x}_{i}-\overline{\boldsymbol{x}}\right)^{2} \quad \mathbf{C}_{y y}=\frac{1}{n-1} \sum_{i=1}^{n}\left(\boldsymbol{y}_{i}-\overline{\boldsymbol{y}}\right)^{2}$

$\mathbf{C}_{x y}=\mathbf{C}_{y x}=\frac{1}{n-1} \sum_{i=1}^{n}\left(\boldsymbol{x}_{i}-\overline{\boldsymbol{x}}\right)\left(\boldsymbol{y}_{i}-\overline{\boldsymbol{y}}\right)$

To assess the ability of the model to reproduce the wind speed spatial variability, we compute the spatial correlation between the models and QuikSCAT of the average and the 95th percentile over 2000-2001 of the daily wind speed for the four boxes covering the areas of strong wind (see Fig. 1). For that, we first interpolate the model results on QuikSCAT 
Table 4. Mean values over 2000-2001 and over the Eastern Basin for the bias, the RMSE, the temporal correlation and the 95th percentile bias of the daily wind speed compared with QuikSCAT for ERA-40, ERA-Interim and each ALADIN simulation. Percentages indicate the ratio relative to QuikSCAT mean value (for bias and RMSE) and $q 95$ value (for $q 95$ bias).

\begin{tabular}{lllll}
\hline \multicolumn{5}{c}{ QuikSCAT: mean value $=6.05 \mathrm{~m} \mathrm{~s}^{-1}, \sigma=3.11 \mathrm{~m} \mathrm{~s}^{-1}, q 95=11.80 \mathrm{~m} \mathrm{~s}^{-1}$} \\
\hline & bias $\left(\mathrm{m} \mathrm{s}^{-1}\right)$ & RMSE $\left(\mathrm{m} \mathrm{s}^{-1}\right)$ & correlation & bias of $q 95\left(\mathrm{m.s}^{-1}\right)$ \\
\hline ERA-40 & $-1.49(-25 \%)$ & $2.45(41 \%)$ & 0.78 & $-2.96(-25 \%)$ \\
ERA-Interim & $-0.96(-16 \%)$ & $2.08(35 \%)$ & 0.80 & $-2.11(-18 \%)$ \\
\hline MED50 & $-1.00(-17 \%)$ & $2.54(42 \%)$ & 0.67 & $-1.71(-15 \%)$ \\
MED50SN & $-0.90(-15 \%)$ & $2.38(40 \%)$ & 0.71 & $-1.58(-13 \%)$ \\
MED50AO & $-1.07(-18 \%)$ & $2.56(43 \%)$ & 0.67 & $-1.83(-16 \%)$ \\
MED125 & $-1.46(-24 \%)$ & $2.87(48 \%)$ & 0.62 & $-2.54(-22 \%)$ \\
MED10 & $-1.02(-17 \%)$ & $2.51(42 \%)$ & 0.67 & $-1.87(-16 \%)$ \\
MED50Int & $-0.98(-16 \%)$ & $2.47(41 \%)$ & 0.69 & $-1.75(-15 \%)$ \\
\hline
\end{tabular}

grid using a triangle-based linear interpolation method and then compute the spatial correlation between the interpolated results and QuikSCAT over the four boxes. For each box, the spatial correlation is computed by taking the correlation (as defined above) between the columnized vector of interpolated results $\boldsymbol{x}$ and the columnized vector of QuikSCAT $\boldsymbol{y}$. QuikSCAT spatial resolution $(25 \mathrm{~km})$ is higher than the resolution used for each simulation, except MED10. This method therefore enables us to examine the quality of the spatial variability representation up to a scale of $25 \mathrm{~km}$. The added value of the $10 \mathrm{~km}$ resolution configuration for scales finer than $25 \mathrm{~km}$ should be assessed thanks to higher resolution dataset, like QuikSCAT L2 dataset used by Chronis et al. (2010).

Figure. 6 shows the map of difference of the relative bias, the temporal correlation, the relative RMSE and the relative $q 95$ bias between respectively MED125, ERA-Interim and MED50 one one hand and ERA-40 on the other. Figure 7 shows the map of those difference between MED50 and the other simulations. For both figures blue corresponds to an improvement (decrease of the absolute biases and RMSE, increase of the correlation).

In the following, we first examine the added value of performing a dynamical downscaling of ECMWF reanalyzes. Second we determine if and how the configuration of the RCM used to perform this downscaling has an impact on this added value.

\subsection{Representation of wind speed in QuikSCAT and the reanalyzed products}

The spatial distributions of the relative bias, relative RMSE, temporal correlation and relative $q 95$ bias for ERA-40 are presented on Fig. 6 (1st line). Wind speed over the Mediterranean Sea is strongly underestimated for years 2000-2001 in ERA-40 (in average by $26 \%$, Table 2), as for other years (Ruti et al., 2007; Herrmann and Somot, 2008; Artale et al.,
2009; Pettenuzzo et al., 2010). Winds are particularly underestimated in the regions of intense winds, especially regions where the chanelling influence of orography is strong: Gulf of Lions, Sicily Strait, southeast and southwest of Crete (Fig. 6a). As can be seen on the $Q-Q$ plots (Fig. 5, thick black curves), the underestimation in ERA-40 is not constant but increases with the strength of the wind. This underestimation of strong wind events is general over the basin as can be seen on the map of the relative $q 95$ bias (Fig. 6d) with a mean $q 95$ bias equal to $-26 \%$ (Table 2). For some regions (e.g. SHELF, MEDOC, Fig. 5b) the $Q-Q$ plot is almost linear, i.e. the relative underestimation is the same for the whole wind spectrum. This is not the case everywhere, particularly in the Eastern Basin (ION, AEGE, CRETE) where the relative underestimation increases with the strength of the wind. Applying a space dependent multiplying factor computed from the mean bias underestimation in order to correct ERA-40 wind fields (Pettenuzzo et al., 2010) seems therefore appropriate for average winds, but does not correct enough the underestimation of intense wind events.

The map of the average wind speed (Fig. 4) shows that the spatial variability of the wind field is strongly underestimated in ERA-40: the contrast between the areas of weak wind and the areas of strong winds is much weaker than in QuikSCAT. Moreover, most of the details of the spatial patterns are not reproduced, in particular those concerning the regions of strong wind in the Bonifacio strait, where no maximum is produced, and south of the Cretan Islands arc, where ERA-40 produces a single spatial maximum instead of two in QuikSCAT.

The defaults observed in ERA-40 are partly corrected in ERA-Interim. First, the underestimation of daily wind speed is significantly reduced over the whole wind speed spectrum, as can be seen on the $Q-Q$ plots (Fig. 5). In average over the basin, the mean bias is reduced by $9 \%$, the RMSE by $7 \%$, the 95th percentile bias by $8 \%$ (Tables 2,4 and 3 ). The temporal 
a) REGIONS
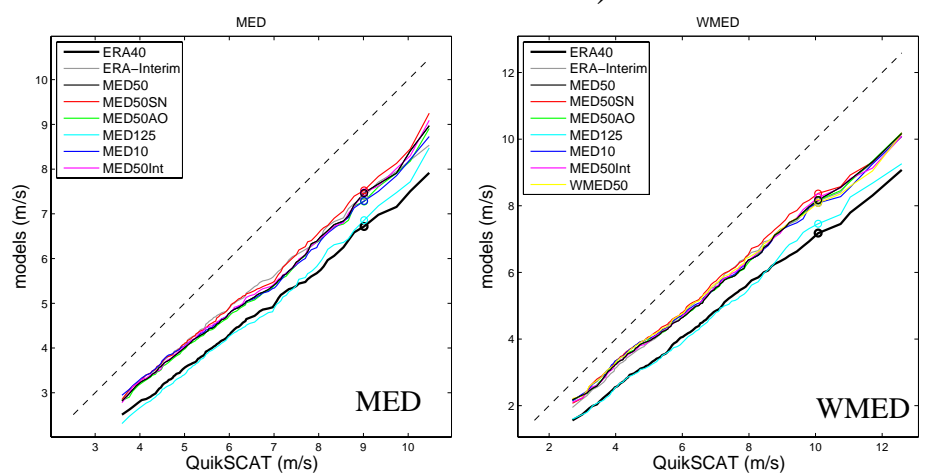

b) POINTS
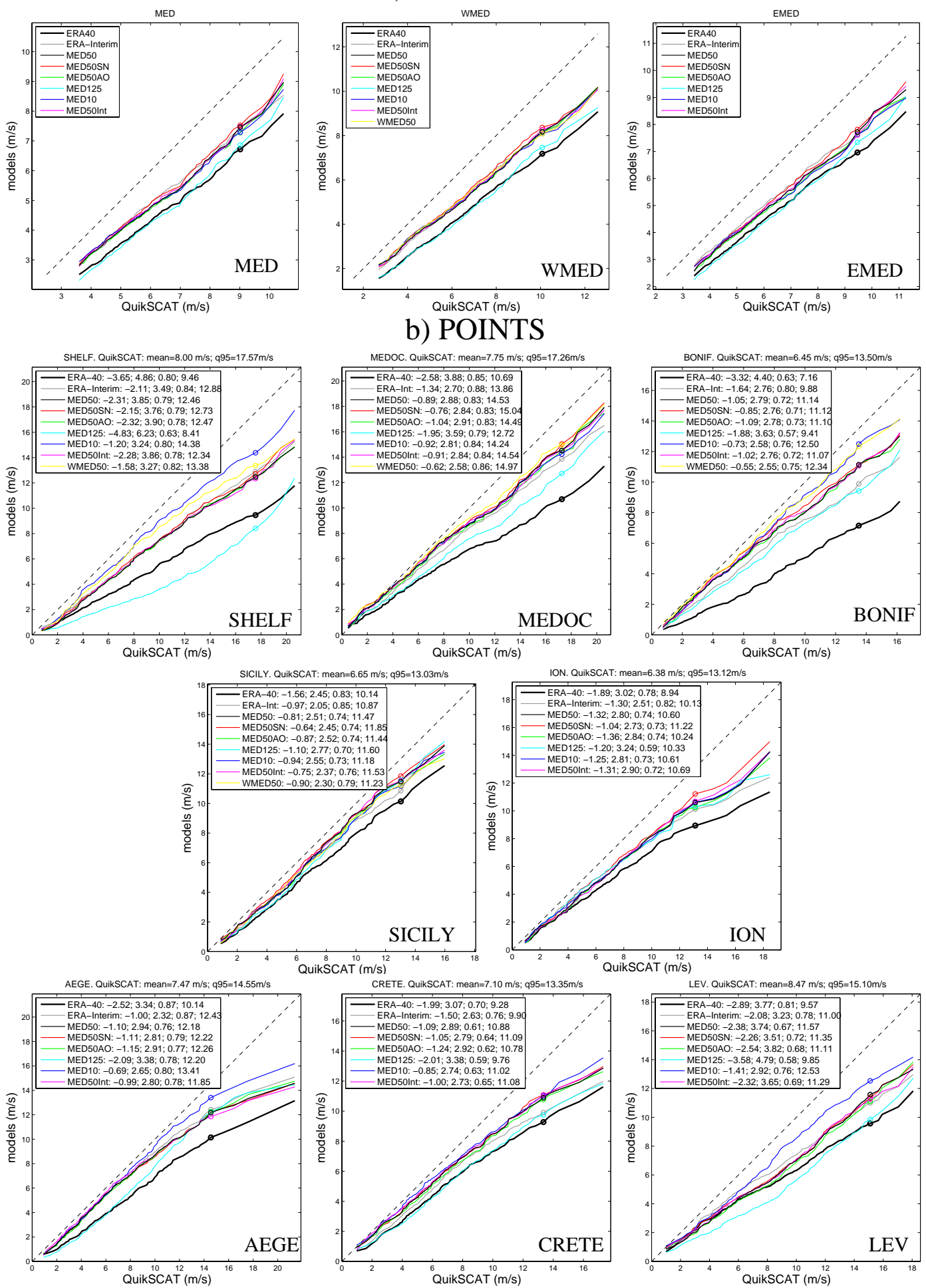

Fig. 5. $Q-Q$ plots (taking the percentiles) of the daily wind speed over 2000-2001 in the models compared with QuikSCAT (a) averaged over the whole Mediterranean Sea (left), the Western Basin (middle) and the eastern Mediterranean (right) and (b) for each point located in a region of strong wind (Fig. 1). The value of the 95th percentile is indicated by a circle. For each point the average value over 2001-2001 and the value of the 95th percentile in QuikSCAT is indicated above each graph for each point. For each model we also indicate in the legend respectively the bias compared to QuikSCAT, the RMSE, the correlation and the value of the 95 th percentile. Unit: $\mathrm{m} \mathrm{s}^{-1}$ 


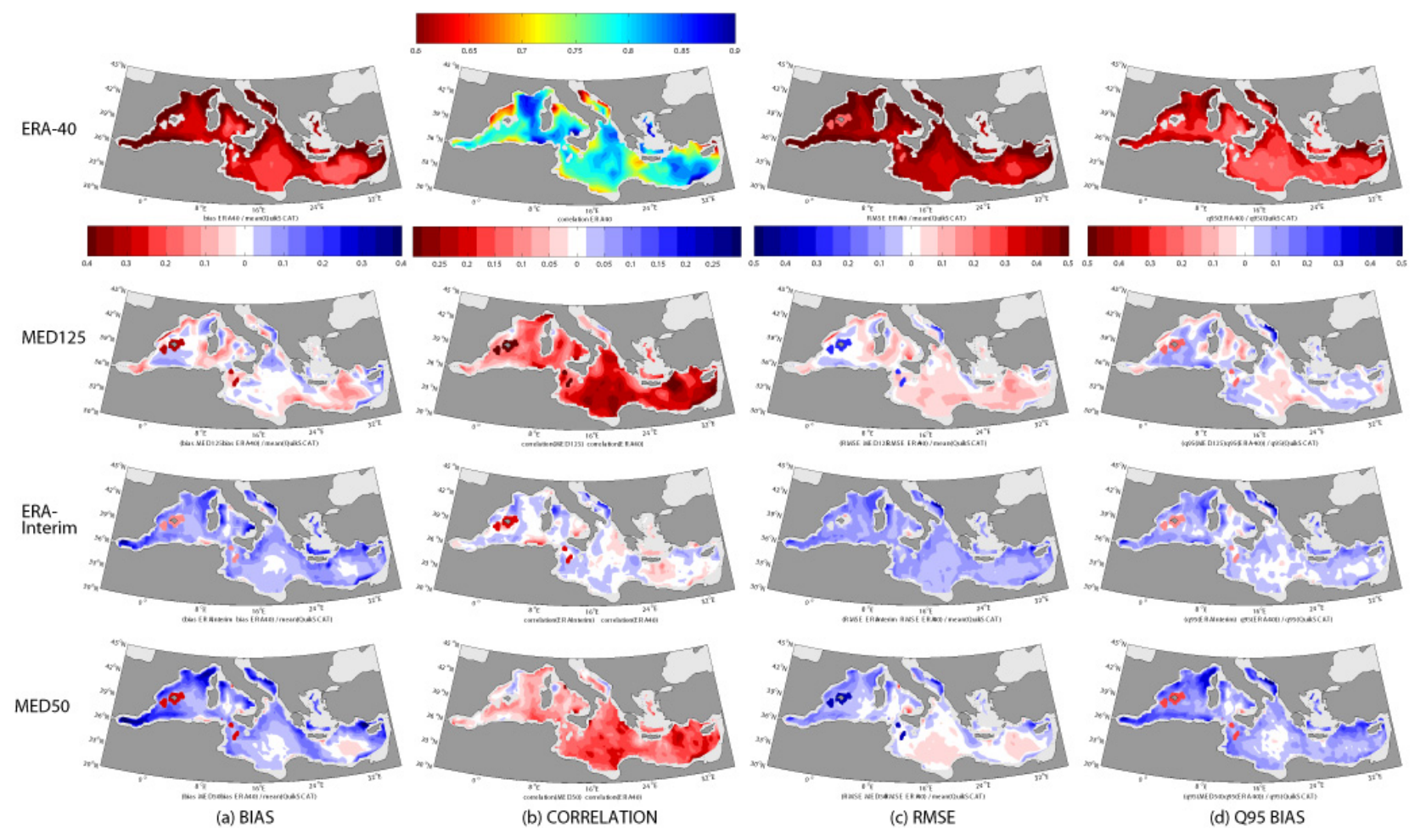

Fig. 6. First line: relative bias, correlation, RMSE and bias of the 95th percentile of the daily wind speed over 2000-2001 in ERA-40 compared with QuikSCAT. Second, third and fourth lines: relative difference between MED125, ERA-Interim and MED50 on one hand and ERA-40 on the other of the bias (a), the correlation (b), the RMSE (c) and the 95th percentile bias (d) of the daily wind speed over 2000-2001 compared with QuikSCAT. The colorbar is the same for each map inside a given column except for the correlation, where the colorbar used for ERA-40 alone is different. Blue corresponds to an improvement (decrease of the absolute value of the negative bias and $q 95$ bias, increase of the correlation and decrease of the RMSE).

correlation is slightly improved (in average by $2 \%$ ). Second, the spatial variability is better reproduced in ERA-Interim than in ERA-40, as can be seen qualitatively on Fig. 4. The spatial correlation for the average wind speed increases by up to 0.34 in the Sicily strait and the correlation for the 95th percentile increases by up to 0.29 in the Tyrrhenian Basin (Table 5).

\subsection{Added value of the dynamical downscaling using MED125, MED50 and MED10}

\subsubsection{Differences between ERA-40 and MED125}

We first determine if the simulation performed using ALADIN-Climate but at the same resolution as ERA-40, MED125, produces results comparable to ERA-40. In MED125 the mean bias is similar to the one observed in ERA-40 (26\% in average over the Mediterranean Sea, Table 2), in average but also locally (Fig. 6a). In some regions, e.g. in the Ionian Basin and in the Levantine Basin, the bias is slightly lower in MED125. The differences between ERA-40 and MED125 $\left(\sim 0.04 \mathrm{~m} \mathrm{~s}^{-1}\right.$, Table 2$)$ are however one order of magnitude smaller than the differences between ERA-40 and MED50 $\left(\sim 0.60 \mathrm{~m} \mathrm{~s}^{-1}\right)$. The underestimation of strong winds is also slightly lower in MED125 than ERA-40 (4\% in average over the Mediterranean, Table 2), but the average difference is $\sim 3$ times smaller than the difference between MED50 and ERA-40 (13\%). These results show that the potential added value due to the dynamical downscaling examined in the following can be attributed to the increase of spatial resolution.

Before to analyze in details the influence of each ALADIN-Climate configuration, we present here the major similarities and differences observed among the simulations. First, all simulations are in average very close, except MED125 which was studied above. Wind speed is underestimated over the whole wind spectrum and in all regions, and maximum wind speed values are always obtained in QuikSCAT. The mean bias error compared to QuikSCAT varies between $-14 \%$ and $-17 \%$ in average over the Western and Eastern basins, the RMSE varies between 39\% and $43 \%$, the $q 95$ bias varies between $-12 \%$ and $16 \%$, and the temporal correlation varies between 0.67 and 0.77 with no more than a 0.04 difference among the simulations (Tables 2, 3 , and 4). More significant differences are obtained locally, in particular near the areas of complex orography (see for 

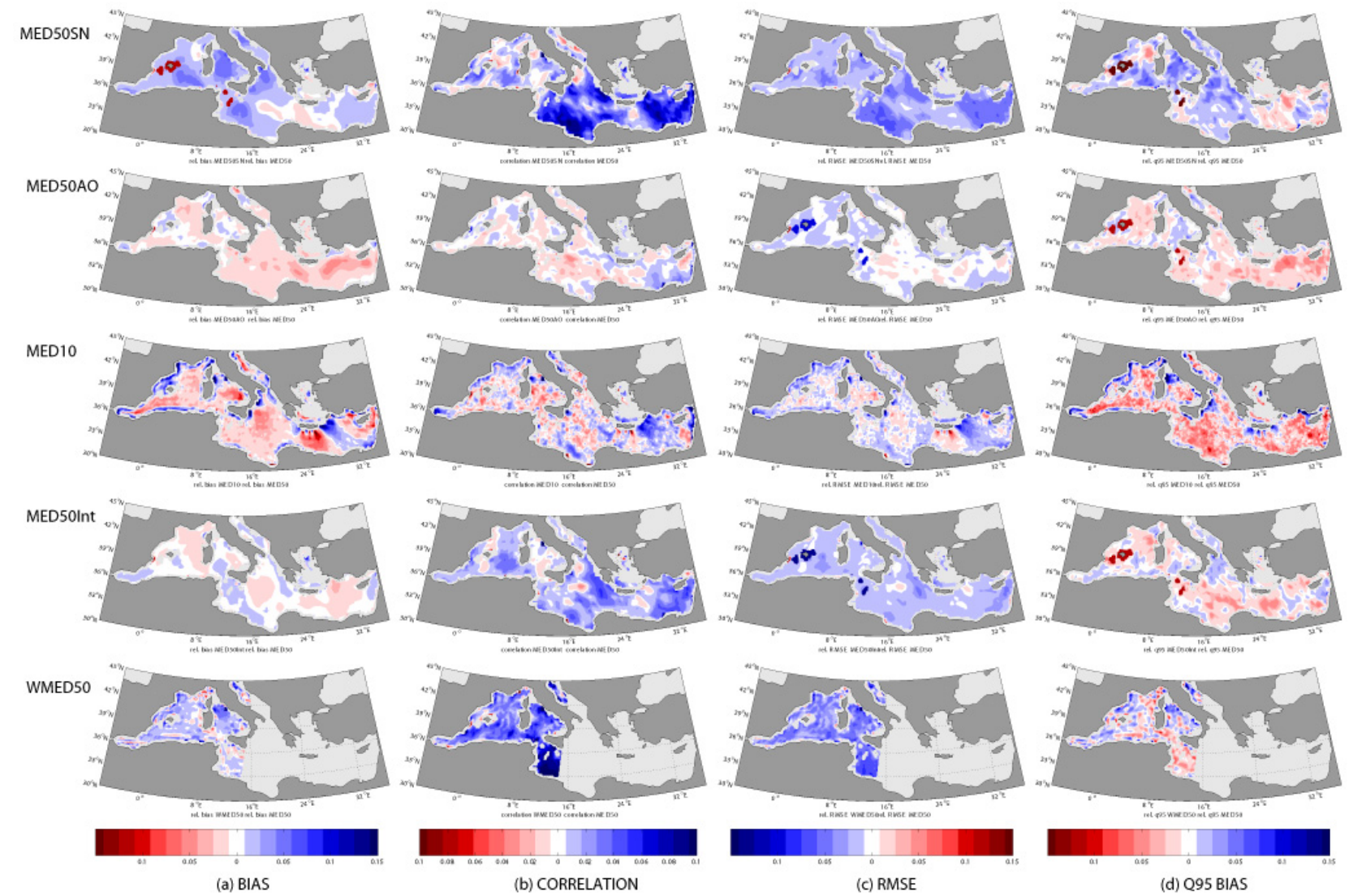

(b) CORRELATION

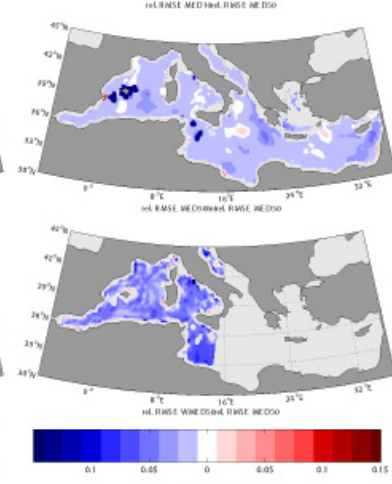

(c) RMSE

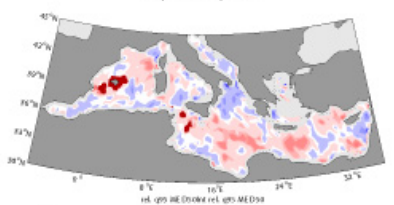

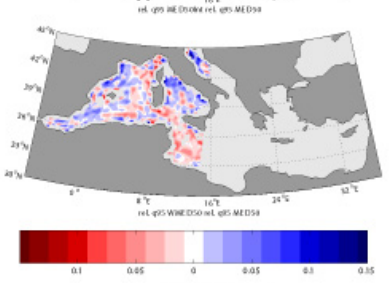

(d) Q95 BIAS

Fig. 7. Relative difference between each simulation and MED50 of the relative bias of the daily wind speed (a), the correlation (b), the relative RMSE (c) and the relative 95th percentile bias of the daily wind speed (c) over 2000-2001 compared with QuikSCAT. The colorbar is the same for each map inside a given column. Blue corresponds to an improvement (decrease of the absolute value of the negative bias and $q 95$ bias, increase of the correlation and decrease of the RMSE).

examples points SHELF, BONIF and LEV, Fig. 5). They are mainly associated to the spatial variability representation (Table 5), and will be discussed in detail in the following.

\subsubsection{Differences between MED50 and the re-analyzed products}

Due to the fact that there is no assimilation, relaxation or spectral nudging in MED50, the temporal correlation with QuikSCAT data decreases in MED50 compared to ERA-40 (in average by 0.09 , Table 2). Globally, the correlation remains nevertheless always larger than $\sim 0.7$, the downscaled dataset reproduces therefore satisfactorily the real chronology. The temporal correlation is relatively homogeneous in ERA-40 ( $\sim 0.78$, Fig. $6 \mathrm{~b}$ and Tables 3 and 4$)$. On the contrary, it progressively decreases in MED50 between the Western Basin (0.74, Table 3) and the Eastern Basin (0.67, Table 4) (Fig. 6b). This is due to the fact that the further, i.e. the more eastwards, we go from the entry of the atmospheric flux into the model domain, the more time the model has to create its own circulation and therefore to depart from the real chronology (Lucas-Picher et al., 2008; Sanchez-Gomez et al., 2008).

Performing a dynamical downscaling enables us to reduce significantly the underestimation of wind speed occurring in ERA-40 (Herrmann and Somot, 2008; Artale et al., 2009, Fig. 6a and c). Increasing the spatial resolution indeed enables us to improve significantly the representation of the orography, that is poorly represented with a $125 \mathrm{~km}$ resolution and strongly influences winds over the Mediterranean Sea (Fig. 3). In average over the basin, the mean bias is reduced by $9 \%$ and the RMSE by $1 \%$ between ERA-40 and MED50 (Table 2). This correction of the wind speed underestimation is obtained for the whole spectrum, and is even stronger for intense events: over the whole Mediterranean the $q 95$ bias is reduced by $13 \%$ (Table 2 and Fig. 5a, thin black line for MED50). The correction is larger in the areas of strong winds of the Western Basin, where it can reach $40 \%$ for the mean and $q 95$ biases and $20 \%$ for the RMSE (e.g. in the Gulf of Lions, Fig. 6a and c), than in the Eastern Basin (Tables 3 and 4, Fig. 5). 
Table 5. Spatial correlation between QuikSCAT and respectively ERA-40, ERA-Interim and each ALADIN-Climate simulation over the four boxes shown in Fig. 1 of the average (left) and the 95th percentile (right) of the wind speed over 2000-2001.

\begin{tabular}{|c|c|c|c|c|c|c|c|c|}
\hline & \multicolumn{4}{|c|}{ Average } & \multicolumn{4}{|c|}{$q 95$} \\
\hline & LION & TYR & SIC & KRIT & LION & TYR & SIC & KRIT \\
\hline ERA-40 & 0.58 & -0.18 & 0.10 & 0.11 & 0.61 & 0.05 & 0.38 & 0.22 \\
\hline ERA-Interim & 0.70 & -0.03 & 0.44 & 0.30 & 0.75 & 0.34 & 0.41 & 0.42 \\
\hline MED50 & 0.75 & -0.08 & 0.54 & 0.42 & 0.77 & 0.37 & 0.39 & 0.59 \\
\hline MED50SN & 0.76 & -0.10 & 0.51 & 0.46 & 0.79 & 0.31 & 0.37 & 0.59 \\
\hline MED50AO & 0.75 & -0.10 & 0.53 & 0.45 & 0.77 & 0.37 & 0.40 & 0.61 \\
\hline MED125 & 0.41 & 0.00 & 0.16 & 0.15 & 0.49 & 0.38 & 0.19 & 0.32 \\
\hline MED10 & 0.88 & 0.37 & 0.67 & 0.71 & 0.87 & 0.40 & 0.46 & 0.73 \\
\hline MED50Int & 0.75 & -0.07 & 0.52 & 0.44 & 0.78 & 0.38 & 0.38 & 0.60 \\
\hline WMED50 & 0.76 & 0.05 & 0.50 & & 0.81 & 0.40 & 0.30 & \\
\hline
\end{tabular}

The representation of the wind speed spatial variability is also improved thanks to the downscaling, as can be seen qualitatively on the maps of average wind speed (Fig. 4). The contrast between the regions of strong and weak winds is better reproduced in MED50 than in ERA-40, as well as the details, in particular the two spatial wind maxima south of Crete. In the regions of strong winds, the spatial correlation of the average and of the 95th percentile of the daily wind speed is better in MED50 than in ERA-40 (the difference varies between +0.10 in TYR and +0.44 in SIC for the average wind, and +0.01 in SIC and +0.32 in KRIT for the 95th percentile, Table 5).

As for ERA-40, the temporal correlation is better in ERAInterim than in MED50. Beside that, the differences between MED50 and ERA-Interim are in average much weaker than the difference between MED50 and ERA-40. First, the average wind speed underestimation is similar in both simulations for the whole wind speed spectrum (Tables 2, 3 and 4 and Fig. 5), though the correction of the 95th percentile is slightly better in MED50 (in average by $4 \%$ ). However differences can be locally larger in regions of intense winds strongly influenced by the orography (see for example points MEDOC, SICILY, CRETE, BONIF, Fig. 5): in those regions the bias correction is better in MED50 (up to $10 \%$ for $q 95$ at BONIF), as well as the representation of wind speed spatial variability (up to $17 \%$ for $q 95$ south of the Cretan arc, Table 5, Fig. 4).

\subsubsection{Differences between MED50 and MED10}

Comparing MED50 and MED10, we examine if increasing the resolution beyond $50 \mathrm{~km}$ still provides an improvement. On average over the basin, the differences between MED50 and MED10 are not significant: the average differences of relative bias, RMSE, temporal correlation and $q 95$ bias are less than $1 \%$ (Tables 2, 3 and 4). However larger differences occur locally (Fig. 7a). The added value of the high reso- lution is localized in coastal regions and regions of intense winds submitted to the influence of a mountainous orography, where the representation of the wind speed variability over the whole spectrum is significantly improved. In those areas, the channeling influence of the topography (Pyrenees, Massif Central, Alps, Corsica, Sardinia, Greek mountains, Aegean islands, Cretan Arc) is strong. Increasing the model resolution beyond $50 \mathrm{~km}$ enables us to better take into account this mountainous orography (Fig. 3) and its effects. This is the case for the Gulf of Lions shelf (the mean bias decreases by $14 \%$ at SHELF, Fig. 5b), at the eastern exit of the Strait of Bonifacio (5\% at BONIF), in the North Aegean Sea (6\% at AEGEE) and southeast of Crete (11\% at LEV). In those regions, the 95 bias is reduced by $10 \%$ to $15 \%$ compared to MED50 (Figs. 5b and 7d). Taking this complex orography better into account also enables us to improve the representation of wind speed spatial variability (Fig. 4), in particular east of the Bonifacio strait (TYR) or south of the Cretan arc (KRIT). Increasing the resolution is the choice of RCM configuration that has the strongest effect on the spatial correlation of average and intense winds (Table 5): the differences between MED10 and MED50 are significantly larger than the differences between MED50 and the other simulations, in particular south of Crete $(+0.29$ for the average and +0.14 for $q 95$ ). Comparing simulations obtained with a $\mathrm{RCM}$ at $20 \mathrm{~km}$ and $7 \mathrm{~km}$ resolution, Lebeaupin Brossier et al. (2011) also concluded that increasing the spatial resolution had a negligible effect on a basin average, but similarly observed very local effects like the improvement of the Mistral representation in the Gulf of Lions.

In the regions of weaker wind and away from the coast, high resolution slightly increases the mean and $q 95$ biases (Fig. 7a and d). This is due to the fact that the contrast between the regions of strong and weak winds is better represented in MED10 (Fig. 4): strong winds in the coastal areas are stronger in MED10 than in MED50 and weak winds in 
the open sea are weaker. This is particularly the case south of Crete, where the spatial patterns of the wind field between the two regional maxima east and west of Crete are better represented in MED10.

\subsection{Analysis of the RCM configuration impact using MED50 and its modified configurations}

We now examine the impact of the choice of the RCM configuration on the representation of the spatial and temporal variability of the wind speed over the Mediterranean Sea. For this purpose we take MED50 as the control simulation with which we can compare every other simulation: between MED50 and the other simulations, we varied each time only one option of configuration.

\subsubsection{Spectral nudging method: MED50/MED50SN}

There is a very weak average reduction of wind speed underestimation in MED50SN. However, as seen in Sect. 3.2.1 the wind speed distribution is similarly represented in MED50 and MED50SN in average and locally (Tables 2, 3 and 4 and Figs. 5 and 7), as well as the spatial variability (Table 5 and Fig. 4). The spectral nudging main added value concerns the representation of the chronology at a daily scale: the correlation is increased respectively in the Western and Eastern basins by 0.01 and 0.04 and the RMSE by $1 \%$ and $2 \%$ (Tables 3 and 4). This improvement is due to the fact that the spectral nudging forces the model to follow the large scale of ERA-40. This large scale mainly drives the atmospheric chronology and the correlation between ERA-40 and QuikSCAT is good homogeneously over the basin (Table 2 and Fig. 6b). In MED50 the correlation decreases more in the Eastern Basin (see Sect. 3.2.2), where the spectral nudging effect is consequently more efficient (Fig. $7 b$ and c): the correlation can be locally increased by more than 0.10 and the RMSE can be reduced by more than $7 \%$.

\subsubsection{Surface boundary: MED50/MED50AO}

The air-sea coupling does not have a significant impact on the representation of the daily wind speed evolution over the whole spectrum. The wind speed distribution and the temporal correlation are almost identical in MED50 and MED50AO in average and locally (Tables 2, 3 and 4 and Figs. 5 and 7), as well as the spatial variability (Table 5 and Fig. 4). This result is in agreement with the work of Artale et al. (2009) who showed that the small difference induced by the coupling concerned mainly the heat fluxes, and that the representation of wind was hardly influenced. This is due to the fact that the coupling between the oceanic and atmospheric model concerns the SST, whose main influence regards the latent heat flux. In the coupled version the atmospheric model is forced daily by the oceanic model SST, whereas the forced version uses ERA-40 monthly SST.

\subsubsection{Domain size: MED50/WMED50}

WMED50 domain was chosen as a test since it could, for example, be used by an ocean modeler interested in oceanic processes that occur in the Northwestern Basin (deep convection, cascading).

Here again reducing the domain size induces a small but not significant improvement of the wind speed underestimation correction homogeneously over the basin and over the whole spectrum (Table 3, Figs.5 and 7). The bias reduction is locally more significant in strong winds areas, namely the Gulf of Lions shelf and the eastern exit of the Bonifacio Strait. The average bias is indeed reduced between MED50 and WMED50 by respectively $9 \%$ and $8 \%$ and the $q 95$ bias by $5 \%$ and $9 \%$ for SHELF and BONIF (Fig. 5). The influence of the domain size on wind speed spatial variability representation is not very homogeneous, though weak (Fig. 4 and Table 5). The influence of the size domain on the spatial variability representation is not very homogeneous, though weak. The local maximum of wind east of Corsica is better represented (the spatial correlation for the average wind over TYR box increases between MED50 and WMED50 by 0.12 ), while the spatial variability representation in the Sicily strait is hindered (the spatial correlation for the average wind decreases by 0.05 over SIC).

The main influence of the domain size concerns the wind chronology. The domain being smaller, the model is less free to develop its own circulation. The temporal correlation with the large scale forcing (ERA-40) and therefore with QuikSCAT is consequently larger (Tables 2, 3 and 4). For the same reasons as already explained above, the temporal correlation improvement is better in the eastern part of the domain, where it can reach 0.10 (Fig. 7b).

\subsubsection{Lateral boundary forcing: MED50/MED50Int}

No significant difference is obtained between MED50 and MED50Int concerning the representation of the wind speed distribution over the whole spectrum, neither in average nor locally (Tables 2, 3 and 4, Figs. 5, 7a and d), and the representation of the average and intense wind events spatial variability (Fig. 4, Table 5). There is a weak improvement of the temporal correlation with QuikSCAT between MED50 and MED50Int ( $\sim 0.02$ over the different basins, Tables 2, 3 and 4 ), associated with the similar correlation increase observed between ERA-Interim and ERA-40. This improvement is smaller than the improvement due to the spectral nudging, in particular in the Eastern Basin ( $\sim 4 \%$ vs. $\sim 10 \%$, Fig. 7 c).

\section{Conclusions}

Wind dataset are used for various scientific purposes: atmospheric process study, operational forecast, hindcast and climate studies, forcing of ocean models, etc. Because of shortcomings due, among others, to their low spatial resolution, 
existing long term reanalysis (ERA-40, NCEP) can not be used directly for those purposes without a preliminary correcting treatment. For example, the underestimation of wind speed and air-sea fluxes is one of the major shortcomings of those reanalysis (Ruti et al., 2007), preventing them from being used for ocean modelling purposes (Herrmann and Somot, 2008). Various methods have been developed in order to correct those defects. A simple method consists in applying the same multiplying factor to the whole wind spectrum (Pettenuzzo et al., 2010), but it does not always correct enough the underestimation of intense winds, stronger than the average bias. Moreover, it does not enable us to deal consistently with the other atmospheric variables. RCMs are now used in order to perform dynamical downscaling of those low resolution reanalysis. Dynamical downscaling is very promising since, contrary to statistical downscaling, it enables us to produce fields where the shortcomings due to the low spatial resolution of the initial reanalysis are corrected and the daily chronology of the atmospheric events is preserved. It also provides forcing datasets where all the variables are consistent with each other and enables us to perform air-sea coupled downscaling. Our goal in this paper was to assess how the configuration of a RCM used to produce downscaled atmospheric fields can influence the representation of wind speed daily variability and of intense wind events over the sea.

Here we used the RCM ALADIN-Climate over the Mediterranean Sea to perform a dynamical downscaling of ERA-40. The atmospheric dynamics in this region is particularly influenced by the strong orography related to the presence of numerous mountains, valleys and islands. We examined the influence of the domain size, the spatial resolution, the use of interactive air-sea coupling and spectral nudging, and the large scale atmospheric forcing. For that we performed a group of 7 numerical simulations over the Mediterranean Sea, changing one parameter at a time. To assess the quality of the representation of daily wind speed variability in each simulation, results were compared with QuikSCAT sea wind satellite observations. We studied the period common to ERA-40 and QuikSCAT, 2000-2001. Comparing QuikSCAT data over different periods and with in-situ hourly buoy data, we showed that the wind speed daily time series obtained thanks to QuikSCAT dataset over 20002001 can be legitimately used as a reference for our purposes. One should, however, keep in mind that QuikSCAT slightly overestimates strong daily winds, the underestimation by ALADIN-Climate may therefore be slightly weaker than assessed here for strong winds.

Performing a dynamical downscaling of ERA-40 $(\sim 125 \mathrm{~km}$ resolution) with ALADIN-Climate at $50 \mathrm{~km}$ resolution enabled us to reduce significantly the underestimation of daily wind speed over the whole wind spectrum, in average and locally, in agreement with previous works (Herrmann and Somot, 2008; Artale et al., 2009). It also enabled us to improve the representation of wind speed spatial variability. Those improvements are mainly related to the increase of the spatial resolution, which enabled us to represent more realistically the complex orography that strongly influences the atmospheric circulation over the Mediterranean region. On the other hand, the realism of the chronology of the downscaled wind fields is worse than for ERA-40. The temporal correlation with the observations decreases all the more that one goes further to the east, i.e. further from the main entrance of the atmospheric flow, where it can loose up to $20 \%$ compared to ERA-40. The correlation however remains $\sim 0.7$, the downscaled dataset reproduces therefore satisfactorily the real chronology.

For average winds, the improvement of ERA-Interim wind speed compared to ERA-40 is similar, as the improvement obtained for the ALADIN-Climate $50 \mathrm{~km}$ downscaled wind speed field. There are several advantages in using the downscaled field. First, the period covered by ERA-Interim is twice shorter than the one covered by ERA-40, which can even be extended until today using ECMWF analysis (see for example Herrmann et al., 2010). The availability of such long hindcasts is of interest when studying events that occurred before 1989 or the long-term variability of the atmospheric and oceanic circulation over the Mediterranean. Second, the spatial and temporal variability of strong winds is better reproduced in MED50. The quality of the representation of the wind speed variability, both spatial and temporal, is important when forcing oceanic simulation, since strong atmospheric events play an important role in oceanic circulation (deep convection, cascading, upwelling ...). Third, the downscaling method used here enabled us to take into account and study air-sea interactions when using the coupled atmosphere-ocean configuration.

Differences associated with the choice of the RCM configuration are globally one order of magnitude smaller than the initial difference induced by the downscaling. The use of spectral nudging has the strongest influence: by forcing the large scale of the RCM to follow the driving dataset, it improves the representation of the daily wind speed atmospheric chronology without hindering the ability of the RCM to reduce the wind underestimation occurring in the driving dataset. The use of a smaller domain has an effect of the same order of magnitude: the correction of the underestimation of the wind speed is slightly improved ( $2 \%$ in average) and the realism of the chronology (temporal correlation and RMSE) are improved by up to $10 \%$. Increasing the spatial resolution up to $10 \mathrm{~km}$ improves the wind spatial variability representation, in particular over coastal areas where the influence of orography is strong. As a result, the bias can be very locally reduced by up to $15 \%$ over the whole spectrum. Statistically, interactive air-sea coupling does not have a significant impact on the representation of daily wind spatial and temporal variability. However, the coupling may influence more significantly the hourly evolution of particularly intense events, and the influence of the time frequency of the coupling should also be investigated in this framework. 
Moreover, the coupled RCM should theoretically be better than the forced RCM since the air-sea interactions are more realistically taken into account. However, some efforts are still necessary in order to improve the representation of wind events in the ALADIN-Climate RCM: improvement of the parameterization of wind gusts, of the physics of the atmospheric boundary layer (turbulence), increase of the number of vertical levels. Finally using another large scale forcing field (ERA-Interim) where the bias is weaker than in ERA40 and the temporal correlation is better only improves the temporal correlation by the same order as the initial difference of the correlation between both forcing fields.

Our results therefore show the relevance of dynamical downscaling to obtain consistent long-term datasets of daily wind over the sea. Moreover, the choice of the optimal configuration of the RCM used to perform this dynamical downscaling is dependent on the scientific objectives. Study of the whole basin or focus on much smaller and/or coastal regions would involve different choices of domain and resolution. Real case study for which a good chronology is important would require spectral nudging, contrary to process study where the goal is to leave the model completely free to develop its own physics. Climate studies for which the influence of a changing SST can become important would require using air-sea coupling. The conclusions obtained might of course be model-dependent, but we honestly trust that the major findings will be helpful for the rest of the community whatever RCM is used.

Finally, additional studies are now necessary to evaluate the quality of the downscaled data set on smaller time scales. For example, how do the choices of configuration examined here, in particular the air-sea coupling, influence the representation of the diurnal and hourly wind variability? At very small temporal $(\sim 1 \mathrm{~h})$ and spatialscales $(<10 \mathrm{~km})$, it would also be necessary to investigate the impact of the use of a non-hydrostatic version of the RCM.

Acknowledgements. This study has been sponsored by the "Forecast and projection in climate scenario of Mediterranean intense events: Uncertainties and Propagation on environment" (MEDUP) project of the program VMC (Vulnérabilité: Milieux et Climat) from the ANR (Agence Nationale pour la Recherche). It is a contribution to the Med-CORDEX (www.medcordex.org) and HyMeX projects (www.hymex.org).

Edited by: P. Drobinski

Reviewed by: two anonymous referees

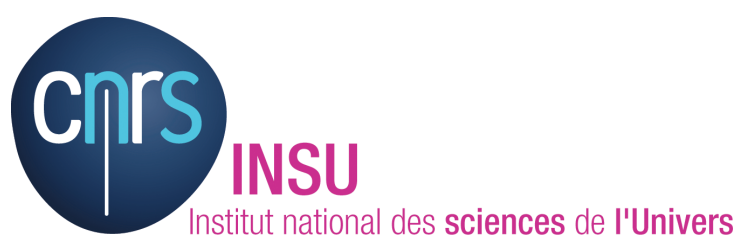

The publication of this article is financed by CNRS-INSU.

\section{References}

Artale, V. S., Calmanti, A. C., Dell'Aquila, A., Herrmann, M., Pisacane, G., Ruti, P. M., Sannino, G., Struglia, M. V., Giorgi, F., Bi, X., Pal, J. S., Rauscher, S., and The PROTHEUS Group: An atmosphere ocean regional climate model for the Mediterranean area: assessment of a present climate simulation, Clim. Dynam., 35(5), 721-740, doi:10.1007/s00382-009-0691-8, 2009.

Bentamy, A., Croize-Fillon, D., Queffeulou, P., Liu, C., and Roquet, H.: Evaluation of high-resolution surface wind products at global and regional scales, J. Operational Ocean., 2(2), 15-27, 2009.

Béranger, K., Mortier, L., and Crépon, M.: Seasonal variability of transports through the Gibraltar, Sicily and Corsica Straits from a high resolution Mediterranean model, Prog. Oceanogr., 66, 341364, doi:10.1016/j.pocean.2004.07.013, 2005.

Béranger, K., Drillet, Y., Houssais, M., Testor, P., BourdalleBadie, R., Alhammoud, B., Bozec, A., Mortier, L., BouruetAubertot, P., and Crépon, M.: Impact of the spatial distribution of the atmospheric forcing on water mass formation in the Mediterranean Sea, J. Geophys. Res., 115, C12041, doi:10.1029/2009JC005648, 2010.

Berrisford, P., Dee, D., Fielding, K., Fuentes, M., Kallberg, P., Kobayashi, S., and Uppala, S.: The ERA-Interim archive, ERA Report Series, Tech. Rep. 1, ECMWF, Shinfield Park, Reading, UK, 2009.

Beuvier, J., Sevault, F., Herrmann, M., Kontoyiannis, K., Ludwig, W., Rixen, M., Stanev, E., Béranger, K., and Somot, S.: Modelling the Mediterranean Sea interannual variability over the last 40 years: focus on the Eastern Mediterranean Transient (EMT), J. Geophys. Res., 115, C08017, doi:10.1029/2009JC005950, 2010.

Biner, S., Caya, D., Laprise, R., and Spacek, L.: Nesting of RCM by imposing large scales, WMO/TD, 987, 30, 7.3-7.4, 2000.

Castellari, S., Pinardi, N., and Leaman, K.: Simulation of the water mass formation processes in the Mediterranean Sea: Influence of the time frequency of the atmospheric forcing, J. Geophys. Res., 105, 24157-24181, 2000.

Christensen, J., Boberg, F., Christensen, O., and Lucas-Picher, P.: On the need for bias correction of regional climate change projections of temperature and precipitation , Geophys. Res. Lett., 35, L20709.1-L20709.6, 2008.

Christensen, J., Kjellstrøm, E., Giorgi, F., Lenderink, G., and Rummukainen, M.: Assigning relative weights to regional climate models: Exploring the concept , Climate Res., 44, 179-194, doi:10.3354/cr00916, 2010.

Chronis, T., Papadopoulos, V., and Nikolopoulos, E.: QuickSCAT observations of extreme wind events over the Mediterranean and Black Seas during 2000-2008, Int. J. Clim., doi:10.1002/joc.2213, 2010.

Colin, J., Déqué, M., Radu, R., and Somot, S.: Sensitivity study of heavy precipitation in Limited Area Model climate simulations: influence of the size of the domain and the use of the spectral nudging technique, Tellus, 62(5), 591-604, 2010.

Demirov, E. K. and Pinardi, N.: On the relationship between the water mass pathways and eddy variability in the Western Mediterranean Sea, J. Geophys. Res., 112, C02024, doi:10.1029/2005JC003174, 2007.

Déqué, M.: Regional climate simulation with a mosaic of RCMs , Meteorol. Z., 19(3), 259-266, 2010.

Déqué, M. and Somot, S.: Extreme precipitation and high resolu- 
tion with Aladin, Idjaras Quaterly Journal of the Hungarian Meteorological Service, 112, 179-190, 2008.

Farda, A., Déqué, M., Somot, S., Horanyi, A., Spiridonov, V., and Toth, H.: Model Aladin as regional climate model for Central and Eastern Europe, Stud. Geophys. Geod., 54, 313-332, 2010.

Geleyn, J.: Interpolation of wind, temperature and humidity values from model levels to the height of measurement, Tellus, 40A, 347-351, 1988.

Gibson, J., Kallberg, P., Uppala, S., Hernandez, A., Nomura, A., and Serrano, E.: ERA Description, ERA-15 Project Report Series, Tech. Rep. 1, ECMWF, Shinfield Park, Reading, UK, 1997.

Guldberg, A., Kaas, E., Déqué, M., Yang, S., and Vester Thorsen, S.: Reduction of systematic errors by empirical model correction: impact on seasonal prediction skill, Tellus, 57A, 575-588, 2005.

Herrmann, M. and Somot, S.: Relevance of ERA40 dynamical downscaling for modeling deep convection in the Mediterranean Sea, Geophys. Res. Lett., 35, L04607, doi:10.1029/2007GL032442, 2008.

Herrmann, M., Somot, S., Sevault, F., Estournel, C., and Déqué, M.: Modeling the deep convection in the Northwestern Mediterranean Sea using an eddy-permitting and an eddy-resolving model: case study of winter 1986-87, J. Geophys. Res., 113, C04011, doi:10.1029/2006JC003991, 2008.

Herrmann, M., Sevault, F., Beuvier, J., and Somot, S.: What induced the exceptional 2005 convection event in the Northwestern Mediterranean basin?, Answers from a modeling study., J. Geophys. Res., 115, C12051, doi:10.1029/2010JC006162, 2010.

Kalnay, E., Kanamitsu, M., Kistler, R., Collins, W., Deaven, D., Gandin, L., Iredell, M., Saha, S., White, G., Woollen, J., Zhu, Y., Leetmaa, A., Reynolds, B., Chelliah, M., Ebisuzaki, W., Higgins, W., Janowiak, J., Mo, K., Ropelewski, C., Wang, J., Jenne, R., and Joseph, D.: The NCEP/NCAR 40-year reanalysis project, Bull. Am. Meteorol. Soc., 77, 437-471, 1996.

Langlais, C., Barnier, B., Molines, J., Fraunié, P., Jacob, D., and Kotlarski, S.: Evaluation of a dynamically downscaled atmospheric reanalyse in the prospect of forcing long term simulations of the ocean circulation in the Gulf of Lions, Ocean Modell., 30, 270-286, 2009.

Lascaratos, A., Roether, W., Nittis, K., and Klein, B.: Recent changes in deep water formation and spreading in the Eastern Mediterranean Sea: A review, Prog. Oceanogr., 44, 5-36, 1999.

Lebeaupin Brossier, C., Béranger, K., and Drobinski, P.: What is the benefit of a high-resolution atmospheric forcing for a regional ocean circulation model? Focus on intense winds and coastal ocean responses in the North-Western Mediterranean Sea, in preparation, 2011.

Louis, J.: A parametric model of vertical eddy fluxes in the atmosphere, Bound.-Lay. Meteorol., 17, 187-202, 1979.

Lucas-Picher, P., Caya, D., de Elia, R., and Laprise, R.: Investigation of regional climate models internal variability with a ten-member ensemble of ten-year simulations over a large domain, Clim. Dynam., 31(7-8), 927-940 doi:10.1007/s00382008-0384-8, 2008.

Madec, G.: NEMO ocean engine, note du Pole de modélisation, Institut Pierre-Simon Laplace (IPSL), France, 27, 1288-1619, 2008.

Myers, P., Haines, K., and Josey, S.: On the importance of the choice of wind stress forcing to the modeling of the Mediter- ranean Sea circulation, J. Geophys. Res., 103, 15729-15749, 1998.

Perry, K.: SeaWinds on QuikSCAT Level 3 Daily, Gridded Ocean Wind Vectors (JPL SeaWinds Project), Guide document, 2001.

Pettenuzzo, D., Large, W. G., and Pinardi, N.: On the corrections of ERA-40 surface flux products consistent with the Mediterranean heat and water budgets and the connection between basin surface total heat flux and NAO, J. Geophys. Res., 115, C06022, doi:10.1029/2009JC005631, 2010.

Radu, R., Déqué, M., and Somot, S.: Spectral nudging in a spectral regional climate model, Tellus, 60A(5), 885-897, doi:10.1111/j.1600-0870.2008.00343.x, 2008.

Romanou, A., Tselioudis, G., Zerefos, C., Clayson, C.-A., Curry, J., and Andersson, A.: Evaporation-precipitation variability over the Mediterranean and the Black Seas from satellite and reanalysis estimates , J. Climate, 23, 5268-5287, doi:10.1175/2010JCLI3525.1, 2010.

Rupolo, V., Marullo, S., and Iudicone, D.: Eastern Mediterranean Transient studied with Lagrangian diagnostics applied to a Mediterranean OGCM forced by satellite SST and ECMWF wind stress for the years 1988-1993, J. Geophys. Res., 108, 123, 2003.

Ruti, P. M., Marullo, S., D’Ortenzio, F., and Tremant, M.: Comparison of analyzed and measured wind speeds in the perspective of oceanic simulations over the Mediterranean basin: Analyses, QuikSCAT and buoy data, J. Mar. Syst., 70(1-2), 33-48, doi:10.1016/j.jmarsys.2007.02.026, 2007.

Sanchez-Gomez, E., Somot, S., and Déqué, M.: Ability of an ensemble of regional climate models to reproduce the weather regimes during the period 1961-2000, Clim. Dynam., 33(5), 723-736, doi:10.1007/s00382-008-0502-7, 2008.

Sanchez-Gomez, E., Somot, S., Josey, S., Dubois, C., Elguindi, N., and Déqué, M.: Evaluation of the Mediterranean Sea Water and Heat budgets as simulated by an ensemble of high resolution Regional Climate Models, Clim. Dynam., doi:10.1007/s00382-0111012-6, in press, 2011.

Sannino, G., Herrmann, M., Carillo, A., Rupolo, V., Ruggiero, V., Artale, V., and Heimbach, P.: An eddy-permitting model of the Mediterranean Sea with a two-way grid refinement at the Strait of Gibraltar, Ocean Modell., 30(1), 56-72, doi:10.1016/j.ocemod.2009.06.002, 2009.

Sevault, F., Somot, S., and Beuvier, J.: A regional version of the NEMO ocean engine on the Mediterranean Sea: NEMOMED8 user's guide, Groupe de Météorologie de Grande Echelle et Climat, CNRM, Toulouse, France, note de Centre, no. 107, 2009.

Simmons, A. and Gibson, J.: The ERA-40 Project Plan, ERA-40 Project Report Series, Tech. Rep. 1, ECMWF, Shinfield Park, Reading, UK, 63 pp., 2000.

Somot, S., Sevault, F., and Déqué, M.: Transient climate change scenario simulation of the Mediterranean Sea for the 21 st century using a high resolution ocean circulation model, Clim. Dynam., 27(7-8), 851-879, doi:10.1007/s00382-006-0167-z, 2006.

Somot, S., Sevault, F., Déqué, M., and Crépon, M.: 21 st century climate change scenario for the Mediterranean using a coupled Atmosphere-Ocean regional Climate Model, Glob. Planet. Change, 63(2-3), 112-126, doi:10.1016/j.gloplacha.2007.10.003, 2008.

Sotillo, M., Ratsimandresy, A. W., Carretero, J., Bentamy, A., Valero, F., and Gonzàlez-Rouco, F.: A high-resolution 44-year 
atmospheric hindcast for the Mediterranean Basin: contribution to the regional improvement of global reanalysis, Clim. Dynam., 25, 219-236, doi:10.1007/s00382-005-0030-7, 2005.

Tonani, M., Pinardi, N., Dobricic, S., Pujol, I., and Fratianni, C.: A high-resolution free-surface model of the Mediterranean Sea, Ocean Sci., 4, 1-14, doi:10.5194/os-4-1-2008, 2008.
Valcke, S.: OASIS User guide, prism 2-5, PRISM-Support Initiative, Report no. 3, CERFACS TR/CMGC/063/73, 2006.

von Storch, H., Langenberg, H., and Feser, F.: A spectral nudging technique for dynamical downscaling purposes, Mon. Weather Rev., 128, 3664-3673, 2000. 